\title{
Aneurysm of the Rabbit Common Carotid Artery Induced by Periarterial Application of Calcium Chloride In Vivo
}

\author{
S. David Gertz, Adi Kurgan, and Daniel Eisenberg \\ Department of Anatomy, The Hebrew University, Hadassah Medical School, Jerusalem, Israel; \\ and Department of Surgery B, Shaarei Zedek Medical Center, Jerusalem, Israel
}

\begin{abstract}
Experimental aneurysmatic dilatation of the rabbit common carotid artery was induced by a single, periarterial application of calcium chloride in vivo. Vessels were fixed in situ after $3 \mathrm{~d}$, 1 wk, 3 wk, $6 \mathrm{wk}$, and 12 wk by intracardiac perfusion of glutaraldehyde and tissues prepared for light, scanning, and transmission electron microscopy. Progressive focal aneurysmal dilatation was seen limited to the site of calcium application with endothelial damage and thrombus formation in areas of irregular luminal contour. Disruption of the elastic network of the intima and media was seen with varying degrees of intimal fibromuscular hyperplasia and medial disorganization.

The calcium-elastic tissue complex was the focus of the inflammatory, arteriosclerotic reaction and subsequent aneurysm formation. The inflammatory cell infiltration initially included primarily neutrophils followed by lymphocytes, plasma cells, monocytes, and multinucleated giant cells. These studies support the hypothesis that disruption of the elastic tissue network of the vascular wall represents an important pathogenetic factor in the initiation of aneurysmal dilatation. In addition, the results of these studies suggest that interaction of calcium with the elastica of the arterial wall may represent an important pathogenetic factor in the initiation of giant cell arteritis.
\end{abstract}

\section{Introduction}

The vast majority of all forms of aneurysm (congenital and acquired) are associated with arteriosclerotic changes in the vascular wall of the dilated segment (1-3), with most of the remaining cases associated with inflammatory processes such as temporal (giant cell) arteritis, polyarteritis nodosa (periarteritis), Kawasaki disease, and syphilitic arteritis (1-5).

It is well known that chronic hypercalcemia represents a risk factor for the development of atherosclerosis (6), and agents that facilitate arterial calcium deposition, such as vitamin D3, promote arteriosclerotic lesions $(7,8)$. Calcification and subsequent fragmentation of the elastic tissue of the arterial wall have long been regarded as a major feature of atherosclerotic lesions and a possible precursor to the development of intimal plaques (9-11). However, the evidence for a pathoge-

Address all correspondence to Dr. S. David Gertz, Department of Anatomy, The Hebrew University, Hadassah Medical School, P. O. B. 1172, Jerusalem, 91010, Israel.

Received for publication 5 March 1987 and in revised form $15 \mathrm{July}$ 1987.

J. Clin. Invest.

(c) The American Society for Clinical Investigation, Inc.

0021-9738/88/03/0649/08 \$2.00

Volume 81, March 1988, 649-656 netic link between calcium deposition and aneurysm formation has not been established. In the present study, aneurysmatic dilatation of the common carotid artery of the rabbit was induced experimentally by a single, periarterial application of calcium chloride in vivo. The associated histopathological changes in the arterial wall at sites of aneurysmal dilatation show features common to atherosclerosis and giant cell arteritis $(12,13)$.

\section{Methods}

19 male rabbits were anesthetized with sodium pentobarbital (30-40 $\mathrm{mg} / \mathrm{kg}$ i.v.) and the common carotid arteries were surgically exposed including incision of the carotid sheaths bilaterally. Calcium chloride solution $\left(0.5 \mathrm{M} \mathrm{CaCl}_{2} \cdot 2 \mathrm{H}_{2} \mathrm{O}\right.$, analytic grade, $\mathrm{BDH}$ Chemicals Ltd., Poole, England, lot 10670, $0.3 \mathrm{ml}$ in double-distilled, deionized $\mathrm{H}_{2} \mathrm{O}$, pH 6.9, 1,170 mosmol/liter) was applied directly to a 1-cm segment of the adventitial surface of the right common carotid artery (RCCA) ${ }^{1}$ so as to keep the entire vessel segment immersed in the solution for 15 min. Sodium chloride $(0.75 \mathrm{M} \mathrm{NaCl}$, analytic grade, E. Merck, Darmstadt, FRG, lot $1118949,0.3 \mathrm{ml}$ in double-distilled, deionized $\mathrm{H}_{2} \mathrm{O}$, pH $6.2,1,360 \mathrm{mosmol} /$ liter) was similarly applied to the contralateral left common carotid arteries (LCCA) as control. The spread of solutions from experimental to control segments was restricted by application of Orabase gel (E. R. Squibb \& Sons, Ltd., London) longitudinally over the trachea. The incisions were then closed and animals permitted to survive for $3 \mathrm{~d}$ (three animals), $1 \mathrm{wk}$ (four animals), $3 \mathrm{wk}$ (four animals), 6 wk (four animals), and 12 wk (four animals).

In four additional animals magnesium chloride $(0.5 \mathrm{M}$ $\mathrm{MgCl}_{2} \cdot 6 \mathrm{H}_{2} \mathrm{O}$, analytic grade, E. Merck, lot 537A 57133, $0.3 \mathrm{ml}$ in double-distilled, deionized $\mathrm{H}_{2} \mathrm{O}, \mathrm{pH} 5.73,1,460 \mathrm{mosmol} / \mathrm{liter}$ ) was applied to the RCCA (instead of $\mathrm{CaCl}_{2}$ ) as additional controls, and $\mathrm{NaCl}(0.75 \mathrm{M})$ was applied to the contralateral LCCA of these animals as before. These animals were killed after $3 \mathrm{~d}$ (two animals) and $3 \mathrm{wk}$ (two animals).

All carotid arteries were fixed in situ by intracardiac perfusion of $1.6 \%$ glutaraldehyde in $0.08 \mathrm{M}$ Sorensen's sodium phosphate buffer (pH 7.4, $310 \mathrm{mosmol} / \mathrm{liter}, 120 \mathrm{mmHg}$, room temperature) without prior exsanguination (14). Arterial segments were excised from the sites of, and distal to, the application of $\mathrm{CaCl}_{2}$ (RCCA) and from similar segments of control vessels (LCCA) to which $\mathrm{NaCl}$ was applied. Specimens were then immersed in $2.5 \%$ glutaraldehyde in $0.1 \mathrm{M}$ phosphate buffer for at least $24 \mathrm{~h}$. Each arterial segment was then cut into three parts by cross section, which permitted preparation of samples of each segment for scanning electron microscopy (SEM), transmission electron microscopy (TEM), and light microscopy (LM).

Specimens for SEM were rinsed in $0.15 \mathrm{M}$ phosphate buffer for at least $1 \mathrm{~h}$ (but not $>24 \mathrm{~h}$ ) and postfixed in $2 \%$ osmium tetroxide in veronal acetate buffer for $45 \mathrm{~min}$. Tissues were dehydrated in increasing concentrations of ethanol and dried in a Polaron critical point drying apparatus. The arteries were then cut in cross section $(0.5 \mathrm{~mm}$

1. Abbreviations used in this paper: EDS, energy dispersive x-ray microanalysis; IEL, internal elastic lamina; LCCA, left common carotid artery; LM, light microscopy; RCCA, right common carotid artery; SEM, scanning electron microscopy; TEM, transmission electron microscopy. 
thick) for determination of cross-sectional area, and the remainder opened longitudinally into three or four parts and mounted on aluminum stubs, coated with gold palladium, and examined in a Philips 505 scanning electron microscope for evaluation of the structural integrity of the luminal surface.

Energy dispersive $x$-ray microanalysis (EDS) was performed on the RCCA ( $\mathrm{CaCl}_{2}$-treated) of two animals permitted to survive for $3 \mathrm{wk}$ as well as control vessels (LCCA) of the same animals treated with $\mathrm{NaCl}$. This elemental analysis was performed on the middle one-third of the media of the 0.5-mm-thick cross sections of vessels prepared for SEM as detailed above. This analysis was performed using a Link $x$-ray analytical system (model 860/500 with standard $152 \mathrm{eV}$ sodium-touranium detector, Link Systems, Ltd., Bucks, England) in association with a JEOL (JSM-35) scanning electron microscope at $25 \mathrm{kV}, 1,500 \times$ magnification, and $0^{\circ}$ tilt. The specimens were analyzed qualitatively and semiquantitatively by estimation of relative concentrations of calcium and other elements from calculations of the area under the curve for each element present in the spectrum studied (spectrum length, 1,024 channels; elements counted for $302 \mathrm{~s}$ ).

Tissues for TEM were rinsed in $0.1 \mathrm{M}$ potassium phosphate buffer (pH 7.6) for $20 \mathrm{~h}$ and postfixed (stained) in $2 \%$ osmium tetroxide in water with $5 \%$ potassium pyroantimonate (pH 7.6) for $90 \mathrm{~min}$ (15). The specimens were again rinsed in phosphate buffer for $15 \mathrm{~min}$ and dehydrated in increasing concentrations of ethanol followed by propylene oxide. Tissues were embedded in Epon 812 epoxy resin (Polysciences, Inc., Warrington, PA), and thin sections (600-1,000 $\AA$ ) were cut with diamond knives using an MT2-B ultramicrotome (Dupont Inc., Sorvall Instruments Div., Newtown, CT). Some sections were stained further with uranyl acetate and lead citrate and others were examined without further staining in a Philips EM 300 transmission electron microscope. Tissues for LM were embedded in glycolmethac- rylate (JB-4, Polysciences, Inc.) and sections ( $2 \mu \mathrm{m})$ were stained with hematoxylin and eosin or with von Kossa's stain or with alizarin red for calcium salts (16). Adjacent specimens were embedded in paraffin and sections were stained with $1 \%$ acid-orcein solution for elastic tissue.

The luminal cross-sectional area of each segment $\left(\mathrm{CaCl}_{2}\right.$-treated, $\mathrm{MgCl}_{2}$-treated, or $\mathrm{NaCl}$-treated) of all animals was determined by planimetric analysis involving direct tracing of the vessel from the screen of the SEM. For this purpose, the specimens were viewed at constant magnification (40X), focus, tilt, and beam acceleration. Planimetric analysis of these tracings was performed using a zero setting, roller planimeter. Wall thickness of each vessel was estimated by measuring from the luminal surface of the endothelium to the adventitial border of the media and calculating the mean of three cross sections of each vascular segment. All statistical comparisons were performed by twotailed $t$ test using the mean square error derived from two-way analyses of variance (17).

Three additional animals were used for angiographic confirmation of changes in luminal diameter. For this analysis both carotid arteries were exposed as described above. $\mathrm{CaCl}_{2}(0.5 \mathrm{M})$ was applied to the RCCA, and $\mathrm{NaCl}(0.75 \mathrm{M})$ was applied to the control LCCA. The animals were permitted to survive for $3 \mathrm{wk}$. Contrast medium (Conray, 60\%, Mallinckrodt, Inc., Science Products Div., St. Louis, MO) was injected into the ascending aorta by way of a cannula inserted into the femoral artery. Angiography was performed on antero-posterior as well as oblique-lateral projection.

\section{Results}

Angiography. Angiographic measurements of the common carotid arteries of three animals to which $\mathrm{CaCl}_{2}$ was applied for
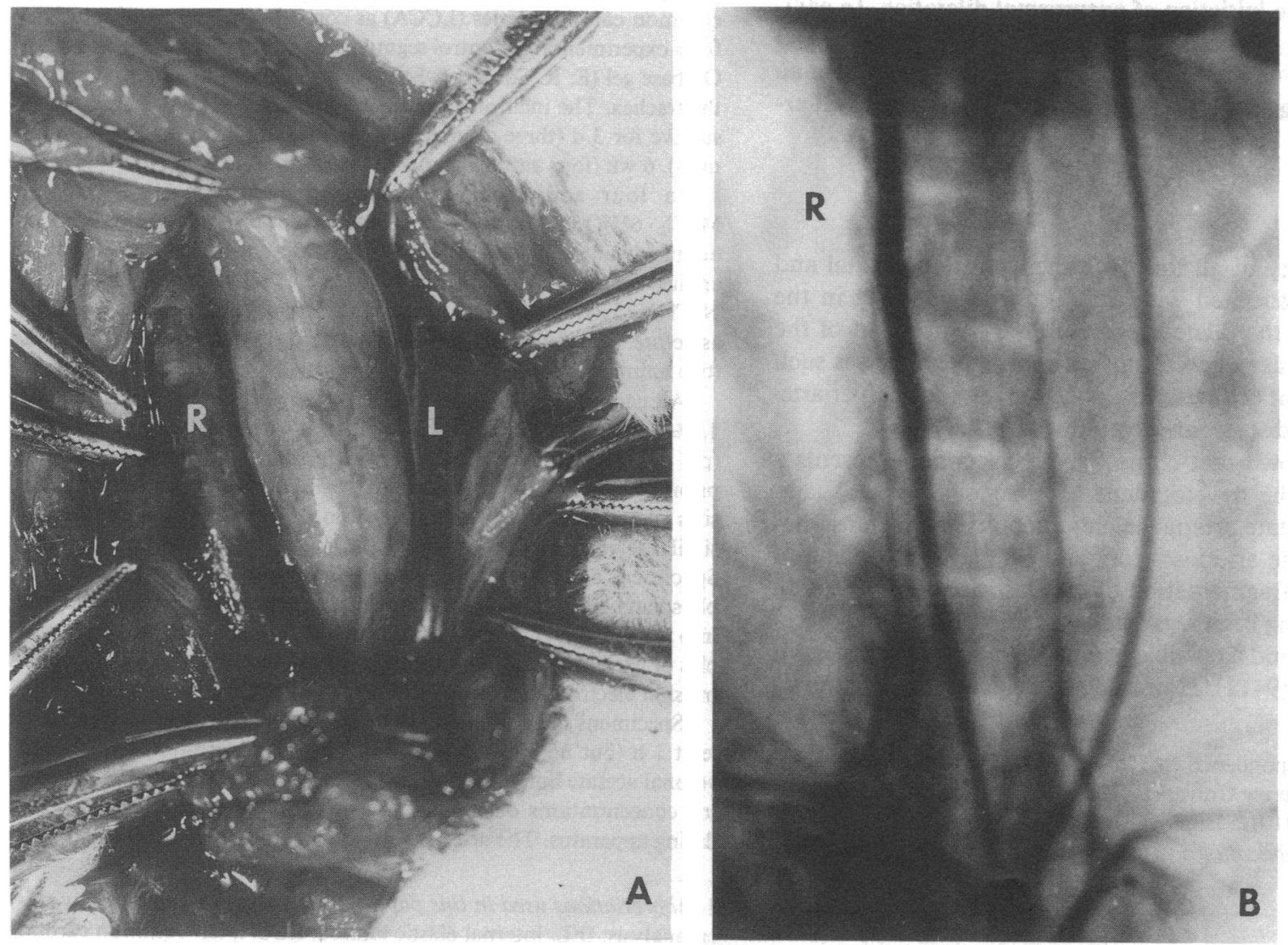

Figure 1. (A) In situ photograph 3 wk after a single, periarterial application of calcium chloride to the RCCA $(R)$. Note marked aneurysmal dilatation compared with the contralateral vessel to which sodium chloride was applied $(L)$. (B) Antero-posterior angiographic projection 3 wk after application of calcium chloride to the RCCA. 


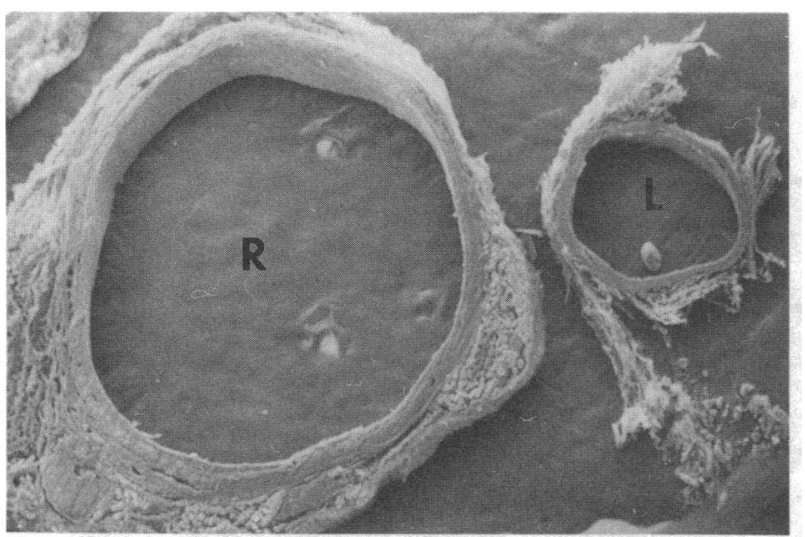

Figure 2. Scanning electron micrograph of cross sections of the common carotid arteries of a rabbit $6 \mathrm{wk}$ after application of calcium chloride to the right vessel $(R)$. Note marked dilatation compared with contralateral control vessel to which $\mathrm{NaCl}$ was applied $(L)$. $(\times 15)$.

15 min showed 30,69 , and $82 \%$ increases in luminal diameter after 3 wk (mean $60 \% \pm 27$ ) as compared with adjacent, distal segments which were not exposed to the solution (Fig. $1 \mathrm{~B}$ ). Likewise, these $\mathrm{CaCl}_{2}$-treated segments showed a 42,75 , and $67 \%$ increase, respectively, in luminal diameter (mean $61 \% \pm 17)$ as compared with the contralateral LCCA to which $\mathrm{NaCl}(0.75 \mathrm{M})$ was applied.

SEM. Planimetric analysis of SEM cross sections of vessels to which $\mathrm{CaCl}_{2}$ was applied for 15 min showed a $22 \% \pm 17$ increase in luminal area after $3 \mathrm{~d}$ as compared with contralateral control vessels to which $\mathrm{NaCl}$ was applied $(P=\mathrm{NS})$. This focal dilatation increased to $152 \% \pm 118$ after 1 wk $(P<0.001)$, to $252 \% \pm 82$ increase after $3 \mathrm{wk}(P<0.001)$, to $319 \% \pm 101$ after 6 wk $(P<0.001)$, and to $381 \% \pm 202$ after 12 wk $(P$ $<0.01$ ) (Figs. 1 and 2). In contrast, vessels treated with magnesium chloride showed no significant change in luminal crosssectional area as compared with contralateral, $\mathrm{NaCl}$-treated control vessels ("increase" of $6 \%$ and "decrease" of $1 \%$ for the two animals killed after $3 \mathrm{~d}$, and an "increase" of $6 \%$ and a "decrease" of $10 \%$ for the two animals after $3 \mathrm{wk}$ ).

SEM examination of the luminal surface of calciumtreated arteries (RCCA) revealed focal areas of endothelial cell damage within the dilated segments consisting of $1-12-\mu \mathrm{m}$ diam crater- and balloon-like vesicular defects $(18,19)$ as well as areas of endothelial cell fragmentation which varied from sloughing of single cells to desquamation of groups of contiguous cells (Fig. 3). Platelet and leukocyte attachment to exposed subendothelium was seen with microthrombi, consisting of platelets and entrapped erythrocytes in these areas of irregular luminal contour (Figs. 3 and 4). No difference was detected in nature or extent of these surface changes over the course of the time periods studied. Segments of the vascular lumen distal or proximal to the site of calcium application were not dilated and showed no irregular luminal contour. The endothelial surface of these nondilated segments, that of the contralateral control vessels (LCCA) to which $\mathrm{NaCl}$ was applied $(0.75 \mathrm{M}, 15$ animals), and that of the $\mathrm{MgCl}_{2}$-treated vessels $(0.5 \mathrm{M}, 4$ animals) were found to be normal in accordance with previous descriptions of endothelial cell morphology $(18,19)$.

$L M$. Light microscopic examination of arterial segments 3 d after calcium treatment was confirmatory of SEM findings concerning the nature and distribution of endothelial damage,
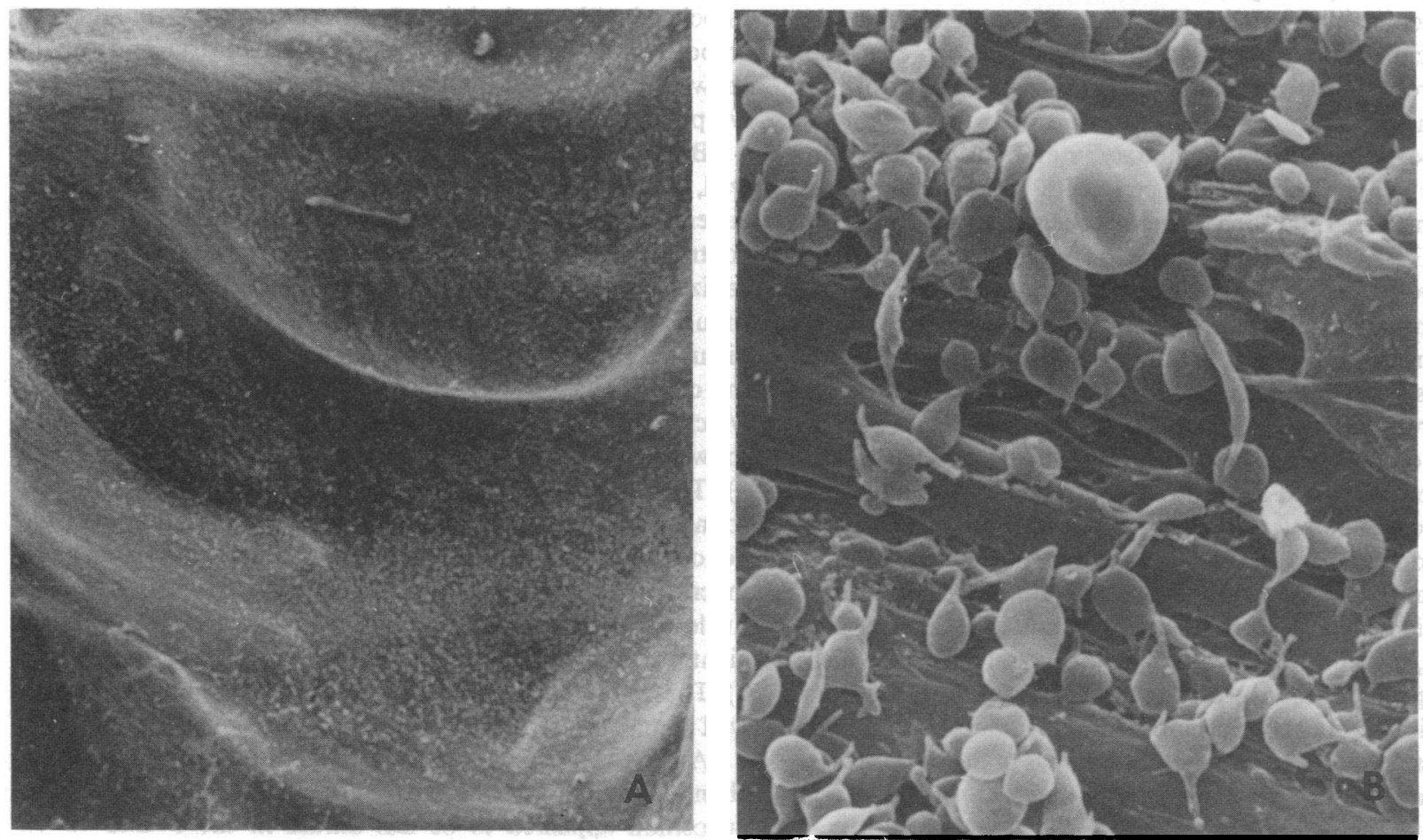

Figure 3. Scanning electron micrographs of the luminal surface of $\mathrm{RCCA}$ at the site of $\mathrm{CaCl}_{2}$ application. Note marked luminal protrusions in low magnification $(A)$ with endothelial desquamation and extensive platelet attachment to exposed subendothelial tissues in the areas of irregular luminal contour seen in $B$. Adjacent areas of these vessels showed normal endothelium identical to that seen in the contralateral control vessels. $(A, \times 29 ; B, \times 2,300)$. 


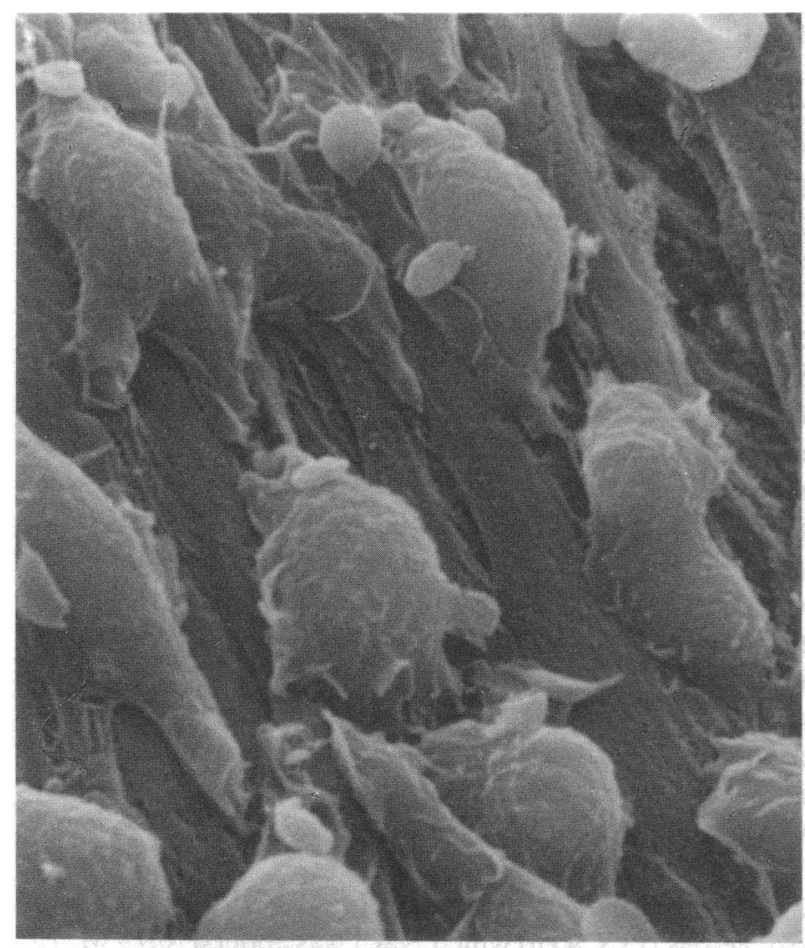

Figure 4. Scanning electron micrograph of RCCA $3 \mathrm{~d}$ after $\mathrm{CaCl}_{2}$ application showing numerous leukocytes adherent to an area of endothelial damage at the site of calcium application $(\times 2,300)$.

platelet deposition, and overall thrombus formation. Within the dilated segments, the internal elastic lamina (IEL), which appeared virtually straight, showed areas of marked discontinuity which stained heaviest with von Kossa's stain for calcium precipitates. In the adjacent, nondilated segments, the elastica remained uniformly convoluted, with minimal disruption, and was not stained.

Leukocytes (shown by hemotoxylin and eosin staining to be mostly polymorphonuclear cells with some monocytes), which constituted the predominant cell type in this time pe$\operatorname{riod}(3 \mathrm{~d}-3 \mathrm{wk})$, were seen attached to the fragmented endothelium as well as to the internal elastic lamina and within the inner (luminal) layers of the media (Figs. 4 and 5). In sections stained for elastic tissue or with hemotoxylin and eosin, these leukocytes were found primarily in areas of disruption of the IEL. Corresponding sections stained with von Kossa's stain and with elastic stain showed prominent calcium deposition within the IEL as well as within the elastica between all layers of the media. The intensity was greatest in the luminal layers and it gradually decreased toward the adventitial layers.

Animals killed after 1 wk showed clear evidence of intimal hyperplasia which, as seen in sections stained for calcium precipitation, was limited to areas of the vessel wall in which calcium precipitates were found. Corresponding sections stained with orcein showed marked fragmentation of the elastica at these sites. Adjacent nondilated areas of the same vessel, in which no calcium precipitation was detected, and in which the elastica appeared intact, showed no evidence of intimal thickening.

Whereas animals permitted to survive for $3 \mathrm{~d}$ showed the calcium to be distributed such that the most intense staining was found in the medial areas closest to the IEL with gradual

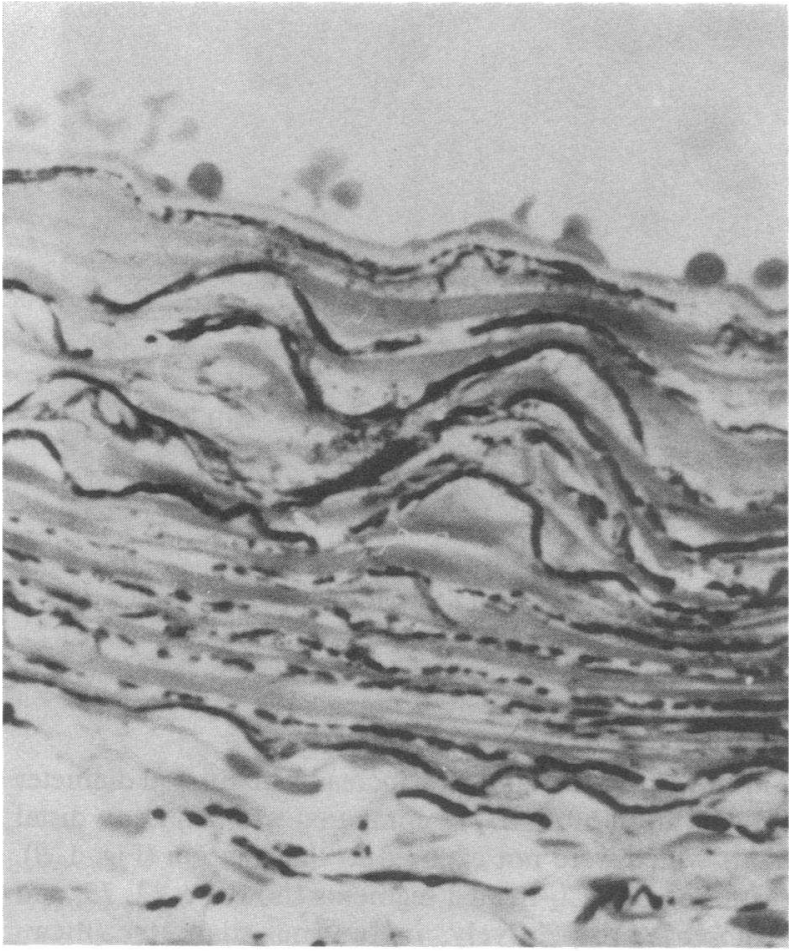

Figure 5. LM section through the RCCA (von Kossa's stain) $3 \mathrm{~d}$ after $\mathrm{CaCl}_{2}$ application showing calcium precipitation within the internal elastic lamina and elastic layers of the media. $(\times 640)$.

decrease in intensity toward the adventitia, animals permitted to survive for $1 \mathrm{wk}$ showed areas of intense calcium precipitation that traversed the entire thickness of the media and was associated with marked disorganization in the orientation of smooth muscle cells. By 1 wk, the adventitia and media showed considerable infiltration of polymorphonuclear cells, lymphocytes, and monocytes.

By $3 \mathrm{wk}$, the IEL could not be detected, and the arterial wall, from the endothelial lining to the medial border of the adventitia, appeared considerably thickened as compared with control specimens. The smooth muscle cells appeared disorganized within a network of abundant loose fibrous connective tissue and the structure of the normal lamellar unit was disrupted (Figs. 6 and 7). Sections stained with orcein showed this connective tissue to be very deficient in elastic tissue. That which could be seen was restricted to focal areas which also showed intense calcium staining with von Kossa (Figs. 6 and 7). This calcium-elastic tissue complex appeared to be surrounded by numerous inflammatory cells which by this time period consisted predominantly of lymphocytes, plasma cells, macrophages, and giant cells. These ranged in type from multinucleated cells with randomly placed nuclei to Langhans type giant cells with circumferentially arranged nuclei (Figs. 6 and 7). These granulomatous foci were seen throughout the vessel wall at sites of calcium application.

Animals killed after 6 and 12 wk showed light microscopic changes similar to those reported after 3 wk. However, calcium deposition appeared to be less diffuse in the 6- and 12-wk groups. It was concentrated primarily in focal areas within the central portions of the media where even more giant cells were found than before (Fig. 7). In all groups, the medial smooth muscle cells that remained appeared normal, but, by $3 \mathrm{wk}$, 


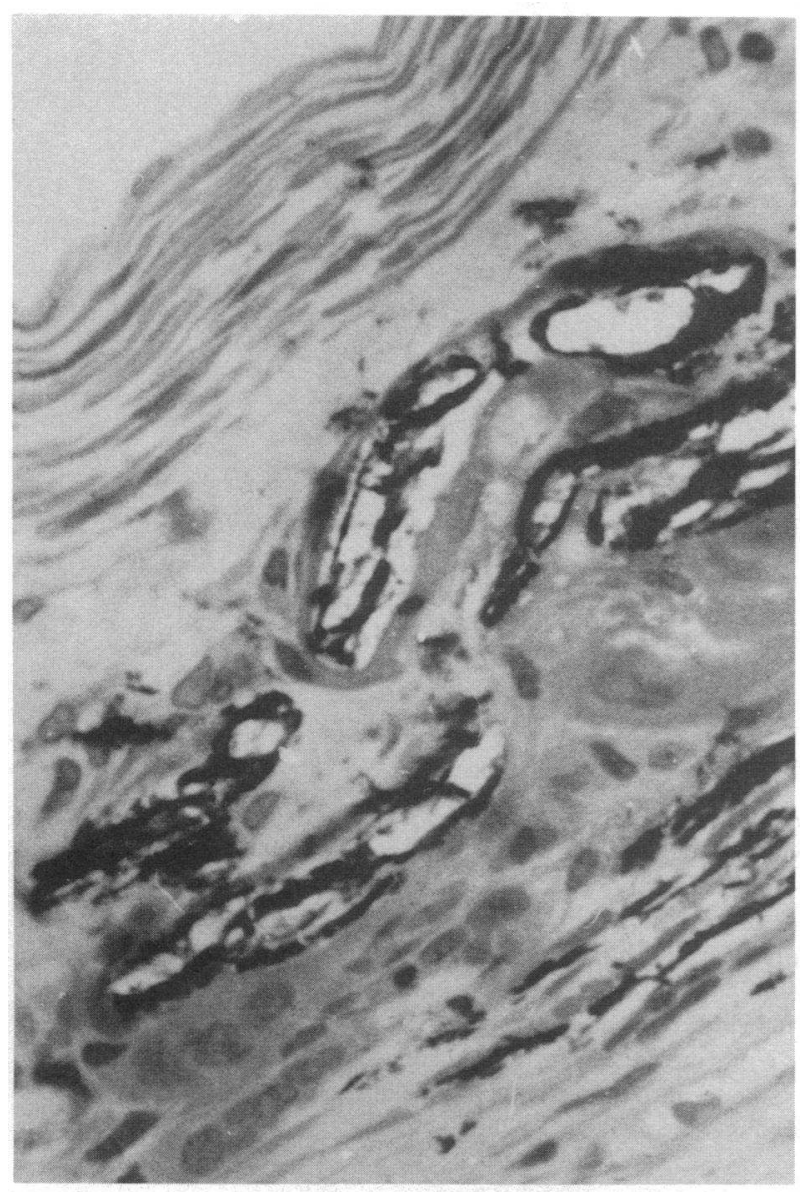

Figure 6. RCCA 3 wk after $\mathrm{CaCl}_{2}$ application (von Kossa's stain) showing numerous giant cells (beneath an area of intimal proliferation, see also Figs. 7 and 8) within the media circumscribing the fragmented calcium-elastic tissue complex. $(\times 680)$.

they were sparse, disorganized, and interspersed with much fibrous connective tissue (fibroblasts and collagen without evidence of elastic tissue) (Figs. 7 and 8).

These light microscopic changes were not found in the vessel segments distal or proximal to the site of calcium application or in any of the control vessels treated with sodium chloride or magnesium chloride.

Measurements of wall thickness (intima plus media) in dilated segments of animals treated with $\mathrm{CaCl}_{2}$ showed a $31 \% \pm 22$ increase after $3 \mathrm{~d}$ compared with contralateral, shamoperated, $\mathrm{NaCl}$-treated controls $(P=\mathrm{NS})$. The wall thickness increased $111 \% \pm 15$ over control by 1 wk $(P<0.005)$, to $279 \% \pm 71$ by 3 wk $(P<0.001)$, to $344 \% \pm 139$ by 6 wk $(P$ $<0.001)$, and to $309 \% \pm 179$ by 12 wk $(P<0.01)$. In contrast, vessels treated with $\mathrm{MgCl}_{2}$ showed no significant change in wall thickness when compared with contralateral, $\mathrm{NaCl}$ treated control vessels ("increase" of $16 \%$ and "decrease" of 7\% (two animals) after $3 \mathrm{~d}$, and "increase" of $16 \%$ and "decrease" of $3 \%$ (two animals) after 3 wk).

$E D S$. EDS of the middle one-third of the media of the cross sections of the RCCA of two animals treated with calcium chloride (survival time $3 \mathrm{wk}$ ) showed a marked increase in calcium deposition compared with the contralateral control vessels to which $\mathrm{NaCl}$ was applied (Fig. 9). Semiquantitative analysis of the RCCA of these calcium-treated vessels showed calcium to account for 70.5 and $74.9 \%$ of the elemental spectrum studied, whereas analysis of the LCCA (NaCl-treated controls) of the same animals showed calcium to account for only 1.36 and " $0 \%$ ", respectively, of the same elemental spectrum.

TEM. TEM of tissues from the dilated segments of calcium-treated vessels $(1,3,6$, and 12 wk) confirmed the calcium precipitation to be limited to within the elastic network of the intima and media (Fig. 10). No fine structural changes were detected within the smooth muscle cells of calciumtreated vessels compared with control. Moreover, sections stained with potassium pyroantimonate showed no obvious difference in the nature or distribution of intracellular calcium between the smooth muscle cells of calcium-treated vessels and control.

\section{Discussion}

In the present study, we have shown that a single, periarterial application of $\mathrm{CaCl}_{2}$ to the rabbit common carotid artery in vivo results in: (a) progressive focal aneurysmatic dilatation at the site of calcium application that is associated with endothelial desquamation with platelet deposition and formation of microthrombi within the dilated segment; $(b)$ deposition of calcium within, and disruption of, the IEL and the elastic tissue of the media with intimal fibromuscular hyperplasia; (c) medial disorganization and inflammatory cell infiltration that include lymphocytes, plasma cells, and multinucleated giant cells in the media and adventitia.

The endothelial damage detected by SEM in areas of aneurysmal dilatation consisted of crater-like vacuolization (18, 19) and focal areas of cellular desquamation with platelet attachment and formation of microthrombi. In adjacent, nondilated segments of the same vessels, no endothelial damage was seen. Likewise, the endothelium of the sham-operated control LCCA to which $\mathrm{NaCl}$ was applied in concentration $(0.75 \mathrm{M})$ to achieve at least as high an osmolarity as the calcium solution, also appeared normal, as did that of the additional control animals to which $\mathrm{MgCl}_{2}$ was applied. This virtually excludes the possibility of an effect of specimen preparation or of the high tonicity of the calcium solution. These findings support the suggestion that the threat posed by aneurysm is not limited to the consequences of rupture or hemostatic thrombosis. Rather, aneurysm may result in a compromise of parenchymal (organ) perfusion also as a consequence of endothelial damage which is known to occur in areas of irregular luminal contour as a result of hemodynamic injury $(1,20,21)$. Thrombus formation, regardless of the initiating mechanism, may result in partial or total arterial occlusion at the site of the aneurysm or result in occlusion of smaller vessels distally following platelet shower or embolization from these sites. In a recent study by Stehbens (3), in which experimental aneurysm of the rabbit common carotid artery was produced by transplantation of a venous autograft, it was suggested that the hemodynamic stresses to which aneurysms (with their irregular luminal contours) are subjected might be responsible for the development secondarily of the arteriosclerotic changes observed. Although the SEM findings in the present study of marked endothelial damage (which was limited to the area of aneurysmatic dilatation, and which was seen in the earliest 


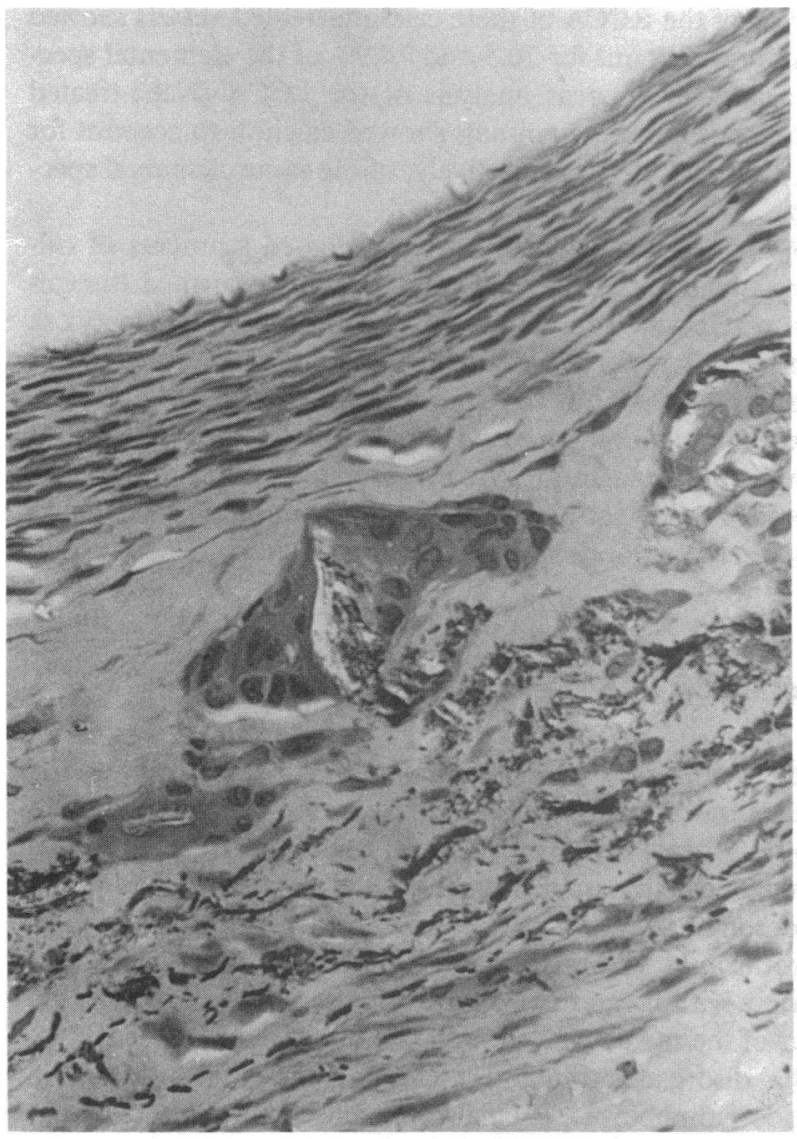

Figures 7 (top) and 8 (bottom). RCCA 6 wk after $\mathrm{CaCl}_{2}$ application showing, in Fig. 7, calcium precipitation within the media, with giant cells showing central vacuolization with fragmented calcium-elastic tissue complexes beneath an area of intimal proliferation. The latter is more clearly seen in the transmission electron micrograph in Fig. 8 of a similar area that shows more clearly the virtual absence of the internal elastic lamina with few smooth muscle cells and much fibrous connective tissue (primarily collagenous) without the normal elastic tissue-smooth muscle cell lamellar unit. (Fig. 7, von Kossa, $\times 350$; Fig. $8, \times 3,500$ )

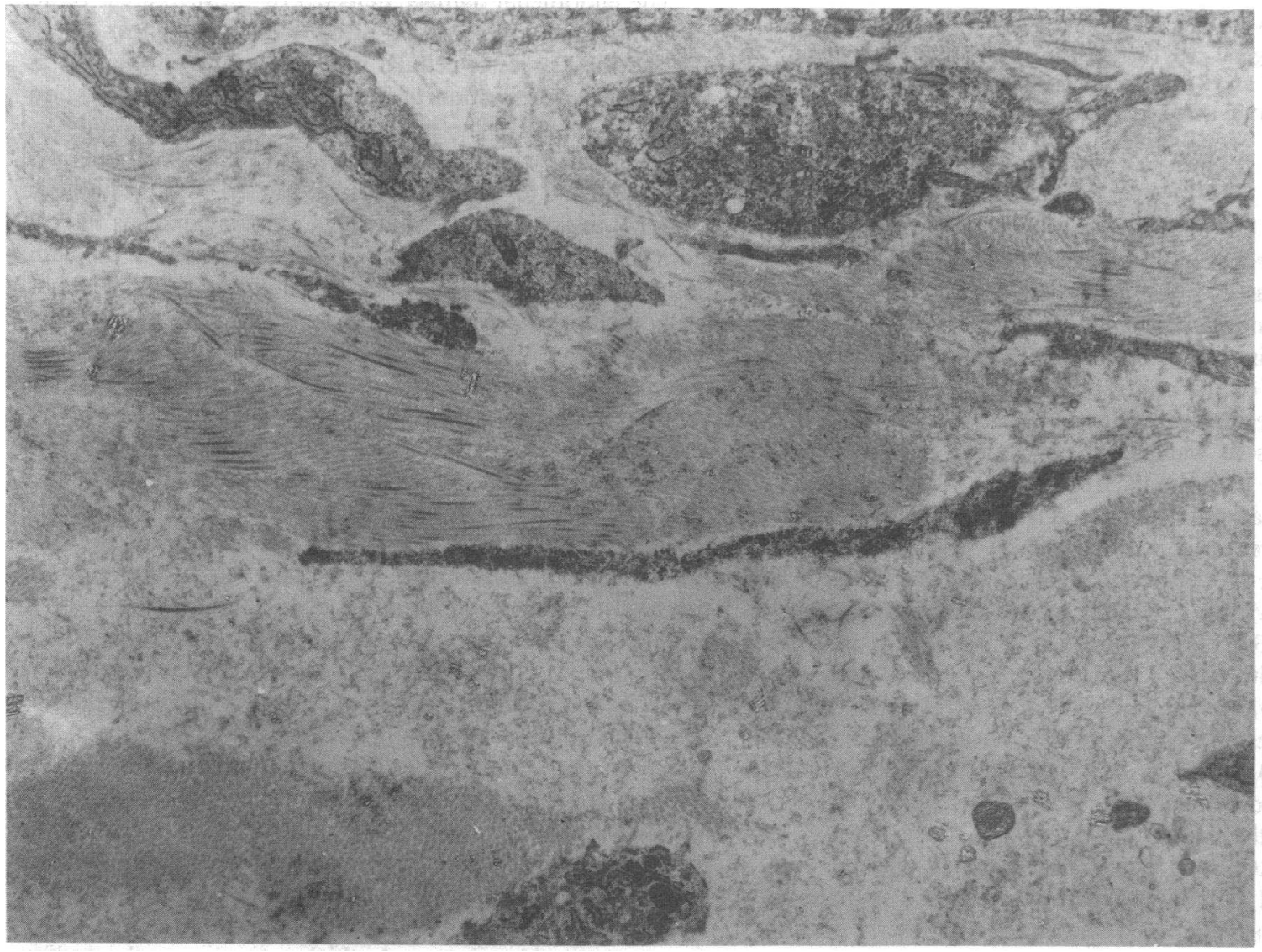



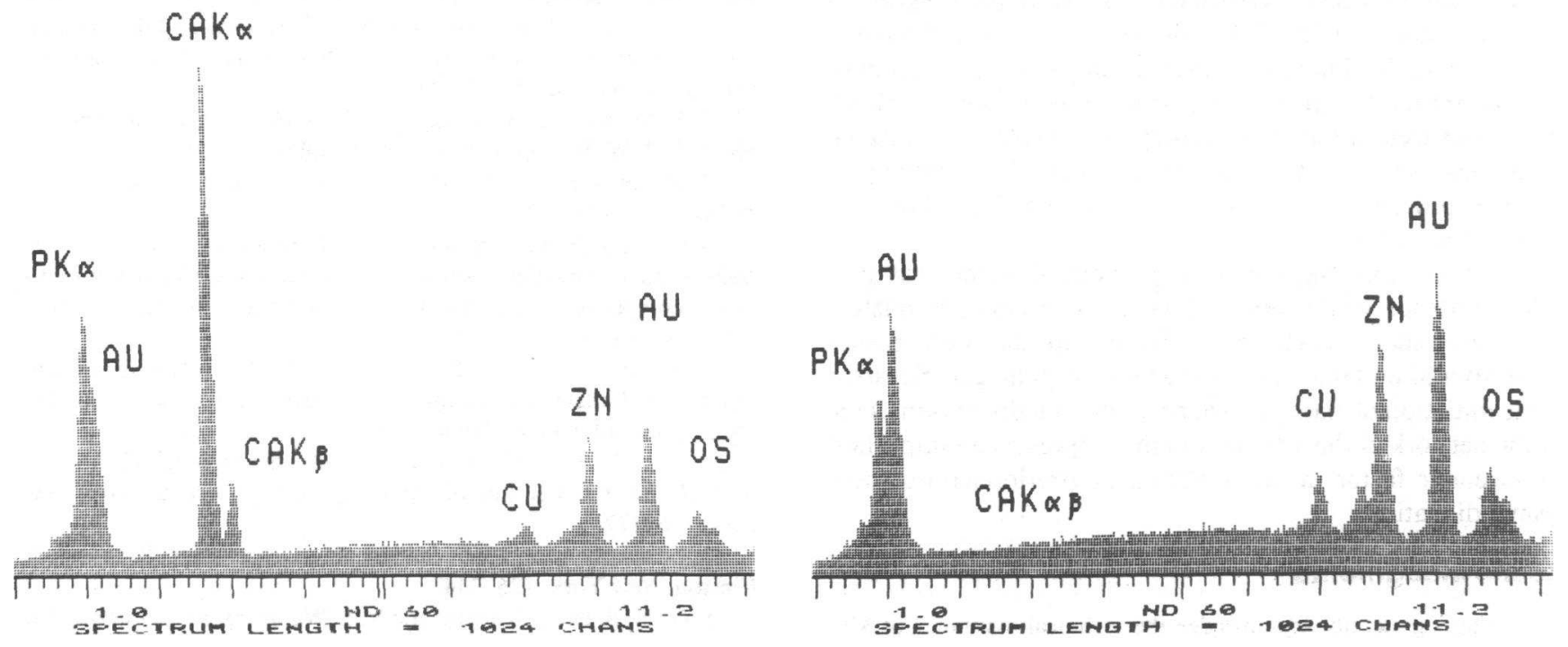

Figure 9. Energy dispersive microanalysis showing marked increase in calcium deposition in the middle one-third of the media of the RCCA (calcium-treated, survival time $3 \mathrm{wk})(A)$ as compared with the contralateral LCCA (NaCl-treated) $(B)$. Semiquantitative analysis has shown the calcium in the RCCA $(A)$ to account for $70.5 \%$ of the spectrum shown, whereas analysis of the LCCA of the same animal $(B)$ showed calcium to account for only $1.36 \%$ of the same spectrum.

stages of this dilatation) support this association, the possibility remains that arteriosclerotic changes in the arterial wall might precede and/or cause the aneurysmatic dilatation. Nonetheless, the marked hemodynamic changes known to occur in such areas of irregular luminal contour would still be expected to exacerbate the damage to the arterial wall $(20,21)$ and further hasten the arteriosclerotic process.

We have shown calcium precipitation to be localized preferentially within the internal elastic lamina and within the elastic network of the media. This is supported by the correlation of findings from LM studies using von Kossa's stain or alizarin red, EDS, and TEM studies using pyroantimonate stain. This is consistent with the known high affinity of calcium for elastin $(22,23)$. However, the precise mechanisms responsible for this affinity remain uncertain. It is known that smooth muscle cell proliferation is associated histologically with disruption of the elastic framework of the arterial wall (11). It has also been suggested that smooth muscle cells respond to mitogenic stimuli such as platelet-derived or macrophage-derived growth factors (24) or low density lipoproteins only once the contractile ability of the cell is impaired (25). The elastic framework is known to be distributed in regular lamellar units between each two monolayers of smooth muscle cells throughout the media. Disruption of this elastic network, coupled with a reduction in the compliance of the vascular wall, should reduce considerably the contractile ability of the adjacent smooth muscle. This would favor aneurysm formation and further increase the effect of mitogenic substances.

Unlike the present experimental model, in most cases of giant cell arteritis the inflammatory changes and the associated intimal fibromuscular hyperplasia, when present, usually result in progressive narrowing or occlusion of the lumen (26).
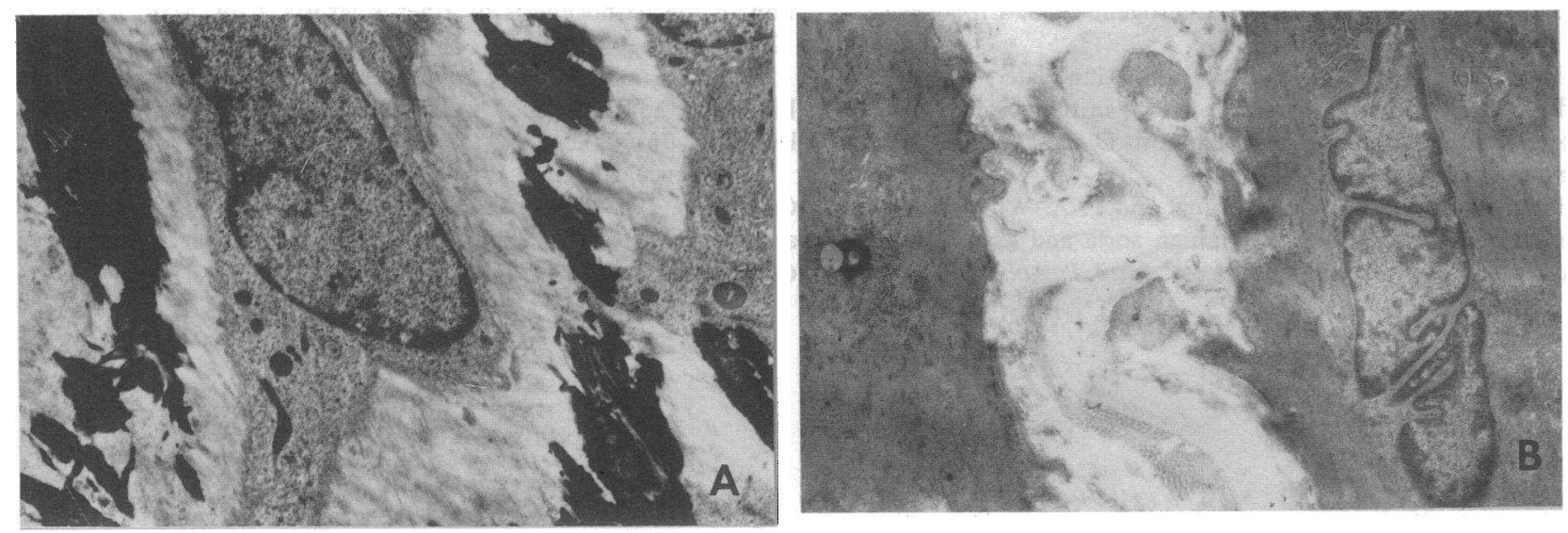

Figure 10. Transmission electron micrographs (pyroantimonate stain) of $A$, RCCA 1 wk after a single periarterial application of calcium chloride showing calcium deposits (black) within the medial elastica. $(B)$ Contralateral sham-operated control vessel showing normal elastica. $(A$, $\times 4,200 ; B, \times 6,490$ ). 
On the other hand, in a minority of cases of giant cell arteritis, this vasculitic process is associated with focal; progressive aneurysmal dilatation $(26,27)$. This does not rule out the possibility that such obliterative changes might occur if animals were permitted to survive for periods longer than the $12 \mathrm{wk}$ maximum seen in the present study. Nonetheless, the mechanism responsible for dictating whether a given vasculitic process will progress to stenosis or to aneurysmal dilatation remains obscure (1).

In conclusion, the present experimental model has provided evidence which supports two, not necessarily related, hypotheses: that interaction of calcium with the elastic tissues of the arterial wall may represent a possible pathogenetic factor in the initiation of giant cell arteritis, and that disruption of the elastic network of the arterial wall may represent an important pathogenetic factor in the initiation of arteriosclerotic aneurysmal dilatation.

\section{Acknowledgments}

The authors gratefully acknowledge the technical assistance of Mrs. Louise Perez.

This research was supported in part by the State of Israel Ministry of Health, the Louis Chor Memorial Fund, the American Physicians Fellowship, Inc., and the Mutual Research Fund of the Hebrew University. Dr. Gertz holds the Chutick chair of cardiac studies.

\section{References}

1. Gaspar, M. R. 1981. Arterial aneurysms. Major Probl. Clin. Surg. 4:176-227.

2. Mitchinson, M. J. 1984. Chronic periaortitis and periarteritis. Histopathology (Oxf.). 8:589-600.

3. Stehbens, W. E. 1985. The ultrastructure of experimental aneurysms in rabbits. Pathology. 17:87-95.

4. De La Monte, S. M., G. W. Moore, M. A. Monk, and G. M. Hutchins. 1985. Risk factors for the development and rupture of intracranial berry aneurysms. Am. J. Med. 78:957-964.

5. Levin, M., P. C. Holland, T. J. Nokes, V. Novelli, M. Mola, R. J. Levinsky, M. J. Dillon, T. M. Barratt, and W. C. Marshall. 1985. Platelet immune complex interaction in pathogenesis of Kawasaki disease and childhood polyarteritis. Br. Med. J. 290:1456-1460.

6. Roberts, W. C., and B. F. Waller. 1981. Effect of chronic hypercalcemia on the heart. An analysis of 18 necropsy patients. Am. J. Med. 71:371-384.

7. Kramsch, D. M., A. J. Aspen, and C. S. Apstein. 1980. Suppression of experimental atherosclerosis by the $\mathrm{Ca}^{++}$-antagonist lanthanum. Possible role of calcium in atherogenesis. J. Clin. Invest. 65:967-981.

8. Morrison, I. M., G. S. Bajwa, R. B. Alfin-Slater, and B. H. Ershoff. 1972. Prevention of vascular lesions in the coronary artery and aorta of rat induced by hypervitaminosis $\mathrm{D}$ and cholesterol-containing diet. Atherosclerosis. 16:105-108.

9. Blumenthal, H, T., A. I. Lansing, and P. A. Wheeler. 1944. Calcification of the media of the human aorta and its relation to intimal arteriosclerosis, ageing and disease. Am. J. Pathol. 20:665-687.
10. Lansing, A. I. 1952. The role of elastic tissue in the formation of the arteriosclerotic lesion. Ann. Intern. Med. 36:39-49.

11. Dible, J. T. 1967. Arterosclerosis of the aorta and the extremities. In Cowdry's Arteriosclerosis. H. T. Blumenthal, editor. Charles C. Thomas, Springfield, IL. 227-247.

12. Robbins, S. L., M. Angell, and V. Kumar. 1981. Basic Pathology. 3rd ed. W. B. Saunders Co., Philadelphia. 270-273.

13. Robbins, S. L. 1967. Pathology. 3rd ed. W. B. Saunders Co., Philadelphia. 590-592.

14. Gertz, S. D., M. L. Rennels, M. S. Forbes, and E. Nelson. 1975. Preparation of vascular endothelium for scanning electron microscopy: a comparison of the effects of perfusion and immersion fixation. J. Microsc. (Oxf.). 105:309-313.

15. Brighton, C. T., and R. N. Hunt. 1978. The role of mitochondria in growth plate calcification as demonstrated in a rachitic model. Am. J. Bone Joint Surg. 60:630-639.

16. Luna, L. G. 1968. Manual of Histologic Staining Methods of the Armed Forces Institute of Pathology. 3rd ed. McGraw-Hill, New York. 176, 177.

17. Edwards, A. L. 1969. Statistical Analysis. Holt, Rinehart, \& Winston, New York. 126, 234.

18. Gertz, S. D., A. Kurgan, and R. S. Wajnberg. 1979. Endothelial damage and thrombus formation following temporary arterial occlusion: effects of pretreatment with aspirin or heparin. J. Neurosurg. 50:578-586.

19. Gertz, S. D., M. S. Forbes, T. Sunaga, J. Kawamura, M. L. Rennels, T. Shimamoto, and E. Nelson. 1976. Ischemic carotid endothelium: transmission electron microscopic studies. Arch. Pathol. Lab. Med. 100:522-526.

20. Fry, D. L. 1976. Hemodynamic forces in atherogenesis. In Cerebrovascular Diseases, P. Scheinberg, editor. Raven Press, New York. 75-95.

21. Gertz, S. D., G. Uretzky, R. S. Wajnberg, N. Navot, and M. S. Gotsman. 1981. Endothelial damage and thrombus formation after partial arterial constriction: relevance to the role of coronary artery spasm in the pathogenesis of myocardial infarction. Circulation. 63:476-486.

22. Hall, D. A. 1967. Elastic tissue alterations in vascular disease. In Cowdrys Arteriosclerosis. H. T. Blumenthal, editor. Charles C. Thomas, Springfield, IL. 121-140.

23. Yu, S. Y. 1967. Elastic tissue and arterial calcification. In Cowdry's Arteriosclerosis. H. T. Blumenthal, editor. Charles C. Thomas, Springfield, IL. 170-192.

24. Barger, A. C., R. Beeuwkes, L. L. Lainey, and K. J. Silverman. 1984. Hypothesis: vasa vasorum and neovascularization of human coronary arteries. A possible role in the pathophysiology of atherosclerosis. N. Engl. J. Med. 310:175-177.

25. Gotlieb, A. I. 1982. Smooth muscle and endothelial cell function in the pathogenesis of atherosclerosis. Can. Med. Assoc. J. 126:903-908.

26. Rodnan, G. P., H. R. Schumacher, and N. J. Zvaifler. 1983. In Primer on the Rheumatic Diseases. 8th ed. Arthritis Foundation, Atlanta, GA. 76-77.

27. Spence, R. K., F. Estella, S. Gisser, R. Schiffman, and R. C. Camishion. 1985. Thoracic aortic aneurysm secondary to giant cell arteritis: a reappraisal of etiology, treatment and possible prevention. $J$. Cardiovasc. Surg. 26:492-495. 